\title{
INVESTIGATING THE WAYS OF LEARNING FROM VERNACULAR ARCHITECTURE
}

\author{
ILKER FATIH OZORHON \& GULIZ OZORHON \\ Department of Architecture, Ozyegin University, Turkey
}

\begin{abstract}
The aim of this study is to investigate the methods for learning from the past and to explore alternative directions/approaches towards transferring past knowledge for the living environments of tomorrow. To achieve this objective, this study suggests a holistic model that combines a variety of layers, directions and methods for utilizing vernacular-architecture knowledge. Three key components of this model are: (1) Learning from Vernacular Architecture (LF-VA), (2) Learning from Experience (LF-E) and (3) Learning from Researchers (LF-R). Based on the scope of this study, each component has been independently examined and their unique characteristics as well as subcomponents have been indicated. Finally, the authors of this study suggested a model that can make alternative situations visible not only for their future researches, but also for other scholars aiming to learn from vernacular architecture. Keywords: learning from the past, vernacular architecture, vernacular knowledge.
\end{abstract}

\section{INTRODUCTION}

"Whether it be built or unbuilt any given architecture work is simply a 'trial'. It is nothing beyond presenting scientific paper or opening the ideas to discussion. What is worthy here is being aware of the concluded and suggested ideas and this can only be achieved by wondering about the past; analyzing, interpreting, associating and questioning what has been seen and heard”

Yürekli, 2011[1].

The roots of architecture go back to the former dates and past experiences. This experience is a great source of inspiration in detecting, analyzing and developing suggestions for the settlement and housing problems of modern age. Trying to comprehend this human experience that was accumulated for ages and seeking this knowledge in designing modern living environments is, beyond anything else, a logical approach. It is a widely accepted fact that there are still many things architecture can learn from vernacular buildings. The most important concern is how we can use vernacular architecture technology to design buildings working well in the future. In this context, the key challenge in the 21 st century is to learn the basic rules and principles of vernacular architecture and to find ways to integrate these rules with development plans to enhance existing habitats and to design new habitats (Masrour and Karbaschi [2]). The key motivation of our study is to seek new ways for learning from the past.

\subsection{Methodology}

In that sense how can architecture environment benefit from accumulation/knowledge that has built up in layers for many centuries? The aim of this study is to investigate the methods for learning from the past and to explore alternative directions/approaches towards transferring past knowledge for the living environments of tomorrow. To achieve that objective this study suggests a holistic model that combines a variety of layers, directions and methods for utilizing vernacular-architecture knowledge. This model integrates three key themes (Fig. 1): (1) Learning from Vernacular Architecture (LF-VA): Existing settlements; 


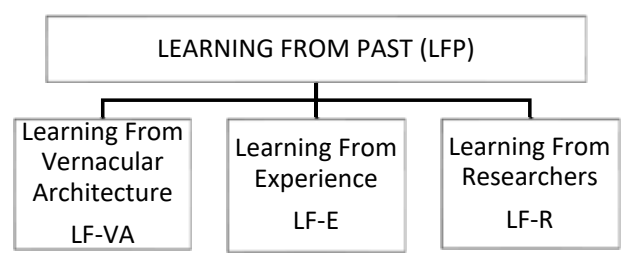

Figure 1: Themes of Learning from Past.

(2) Learning from Experience (LF-E): from those who learned from vernacular, (3) Learning from Researchers (LF-R).

Within the context of this study, each theme will be independently analyzed and each one will be presented with its unique dynamics. In the end, all of the collected data will allow us to suggest a holistic guideline-model that can let us explore alternative ways for transferring knowledge from vernacular architecture.

\section{AN APPROACH FOR LEARNING FROM THE PAST}

\subsection{Learning from Vernacular Architecture (LF-VA)}

The first theme to handle focuses on gaining knowledge from vernacular settlements via analyses and observations while also presenting this knowledge for the use of architectural-science environment in a systematic point of view. Identifying and documenting a location/settlement by using alternative methods and architectural representation tools is vital as it offers a background for prospective studies. Needless to say, vernacular examples offer a rich repertoire of architectural knowledge not only in the field of design, innovations, and sustainable techniques but also in other theoretical fields (Rashid and Ara [3]). If the aim is truly to learn from vernacular architecture, what is needed is a holistic, integrated and critical approach that complements the study of the environmental qualities and performance of vernacular architecture with an examination of its social, political and economic aspects (Velinga [4]).

There are alternative dynamics to achieve knowledge transfer from vernacular architecture via existing settlements. Mainly these dynamics can be grouped under two titles (Fig. 2). Within the context of this study the first title is defined as built environment; whilst the second one as socio-cultural environment. Although built environment and socio-cultural environment are two interconnected and almost inseparable concepts, in reality, they exhibit distinctively dissimilar structures. Hence examining the two structures independently and dealing with their subtitles accordingly holds significance both to simplify the comprehensibility of vernacular architecture and to learn from vernacular architecture.

Built environment includes in itself a list of different structure-scales. Rapaport [5] also argues that "humans cannot examine only an isolated single building; rather s/he must analyze connection of the building with the components of whole system; open spaces, roads, other settlements, neighbors, neighbor settlements and occasionally the entire region (and its ingredients under all circumstances and situations); hence it may be the logical approach to utilize a myriad of scales to comprehend built environments. These scales can be listed as settlement (general layout decisions, topography relations, orientation principles...), buildings (space organization, local spatial solutions), elements of a building (system, material...). 


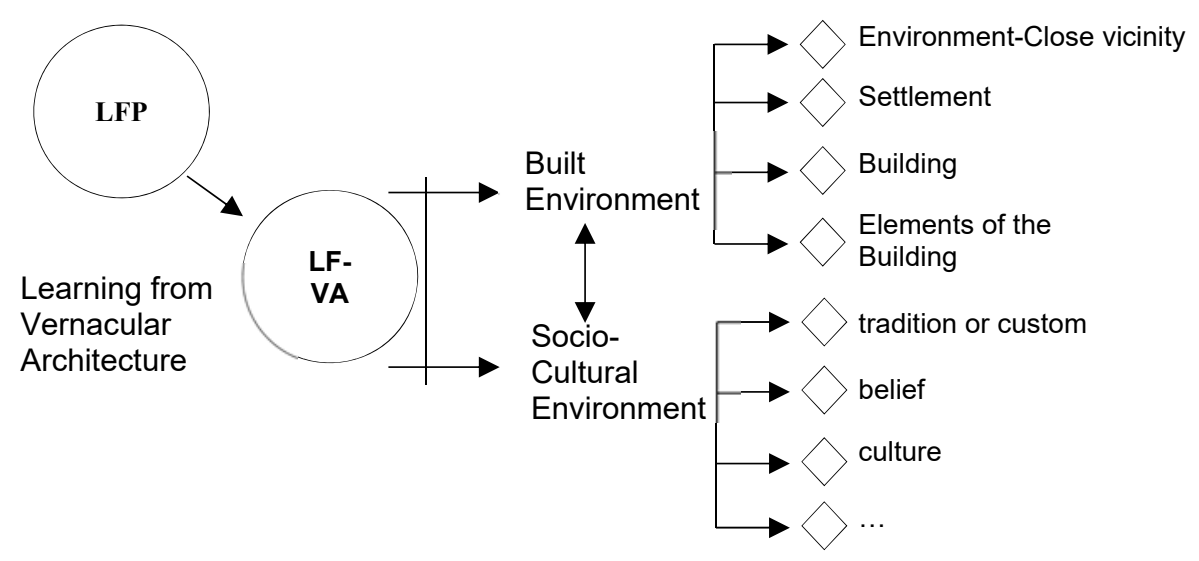

Figure 2: LF-VA (Learning from Vernacular Architecture).

In the words of Hillier and Hanson [6] in vernacular architecture, the existence of space in social structure is provided with the continuity of unwritten traditional rules. Socio-cultural environment is a multi-layered and complex structure that includes in itself a variety of structures such as tradition, culture, norms and values system and this complex body also includes key arguments that allow to form the model for structural vernacular-architecture. All in all, socio-cultural environment is a significant point for researchers motivated to learn from vernacular architecture and also a great field of research that necessitates an interdisciplinary analysis.

Of course, environmental conditions and spatial requirements are in constant change. Therefore, vernacular architecture products may not fully meet expectations with their current state. Nevertheless, again by learning from them, it may be possible to develop low-cost traditional solutions or innovative solutions based on vernacular construction methods (Meir and Roaf [7])

\subsection{Learning from Experience (LF-E)}

The second theme of this study can be outlined as examining architectural influence of those architects using vernacular architecture knowledge in architecture productions and trying to understand their methods. In other words, what it means is that learning from the experiences of architects, in one sense, tries to unveil vernacular architecture knowledge through identifications, observations and releases while in another sense putting learnings from this architecture-philosophical motto, in particular, into the center of this unique architecture approach and using vernacular architecture as a reference in creating a structure is their goal. To that end, the authors suggested (Ozorhon and Ozorhon [8]) in their earlier studies two interlinked directions. The first direction is analyzing discourses/philosophies of these architects and the second direction is examining architectural products they exhibited which are fed by their discourses (Fig. 3). 


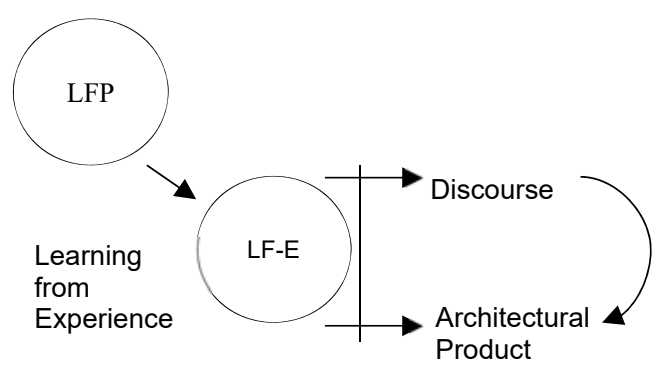

Figure 3: LF-E (Learning from Experience).

It is obvious that analyzing architectural influence of Fathy, Correa and similar architects is instructive from some aspects. Indeed, they continue to be a source of inspiration and a part of architecture education with their architectural products and discourses. They oppose commercialized architecture dominating the whole globe and acting as a mere commodity that only pays heeds to what is popular; rather scholars hope to analyze culture knowingly and holistically with an aim to ensure the continuity of culture and bridge the past with the future. Although a number of approaches criticize the philosophy they follow, the common trait differentiating these names is not the destination, but the method followed to reach this destination. The arguments they propose and their approach to continue the same determination in their architectural activities, question how these life dynamics are reflected on architecture and viewing and seeking the "human" with their unique personal features and components of social unity and classifying the characteristics of "place" as the key component of their designs will continue to be a guideline for architecture researchers and practitioners in all ages (Ozorhon and Ozorhon [8]).

Hence we believe that a secondary but effective method for learning from vernacular architecture is learning from the experiences of architects nourished from vernacular architecture.

\subsection{Learning from Research (LF-R)}

The third theme is to learn via transferring knowledge from the works of architecture researchers. Currently there is a vast accumulation for this type of learning that keeps on increasing each day. Some of the applied tools are; research projects, dissertations, articles and books (Fig. 4). Within that context (LF-R) two different methods can be used. The first one is individually using researches/research findings. For instance, in a research project a model or strategy that is developed by learning from vernacular architecture can be utilized or honed in designing the new one. This method is viewed as the most effective and powerful method to create innovative future projects by integrating past knowledge with technological advancements. On the other hand, the second way for LF-R could be attempting to $\mathrm{read} /$ understand the researches as a single unity. This method would enable to create holistic knowledge that is based on the accumulated knowledge in relevant literature and focusing on interpreting such knowledge. Consequently, even though accumulation created in LF-R is a secondary source of learning from vernacular architecture, thanks to its enriched structure with the contribution of studies in other disciplines, the method should be valued as a vital road to guide the future. 


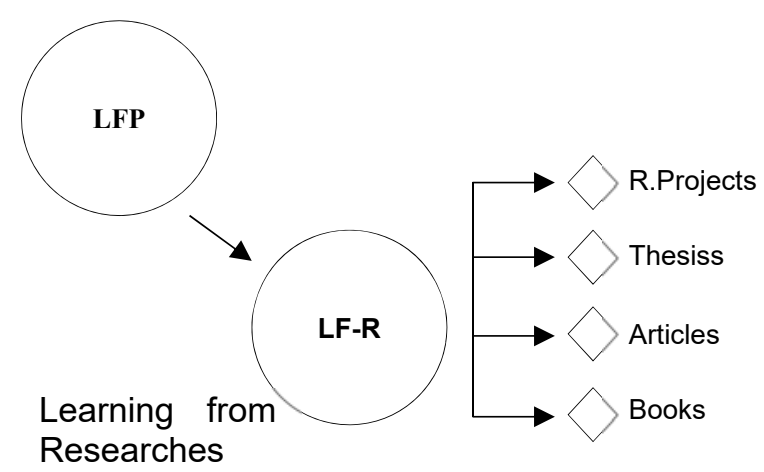

Figure 4: LF-R (Learning from Researches).

Here it is also significant to add Rapoport's interpretation quoted by Asquith and Vellinga [9]. "So far, Rapoport notes, the field of vernacular studies has been in its 'natural history' stage, 'describing and documenting buildings, identifying their variety, classifying them and so on'. However, in order for the vernacular to teach lessons that are relevant to the future, a more problem-oriented, comparative and integrative stage that leads to explanatory theory needs to be entered".

\section{HOLISTIC EVALUATION}

In the second part of this study, subthemes of learning from past (LFP) in general and in particular learning from vernacular architecture (LF-VA) have been presented with their unique dynamics. Yet there is a significant point that any researcher searching for means to transfer knowledge from vernacular architecture must remember. That is to say, even though the nature of this research necessitated the analysis of each theme independently, one must treat vernacular architecture as a complex unity that includes many interconnected relations and layers. Thus, not every single dynamic should be viewed as an independent entity but interpreted in regards to its link with others and facts of the time it belongs to.

This paper aims to search alternative road for learning from vernacular architecture. It is no doubt that this is a vast research subject and since what is mentioned here is a location-dependent architecture and its products, it is suggested to endlessly develop these studies based on each new location. Thus, it has been the aim of this paper to suggest a holistic-base model not dependent on a specific location. Fig. 5 exhibits components of learning from vernacular architecture and interlinks between these inner components.

In that case primary source in learning from vernacular architecture is LF-VA, secondary sources are LF-E and LF-R. Therefore, the system is fed by LF-VA, LF-E and LF-R. To put this clearly vernacular architecture itself, learners from vernacular architecture and vernacular architecture researchers offer the main data that fill the knowledge pool. On the other hand, experience and research feed one another reciprocally. In this system key factors that vitalize knowledge pool are models, concepts and theories; primary concepts are documentation, conservation, adaptation and innovation. How to transfer data that make up knowledge pool to the future and architecture environment of tomorrow is indeed a critical matter. Some of the key concepts that might be vital are identity, continuity and sustainability. 


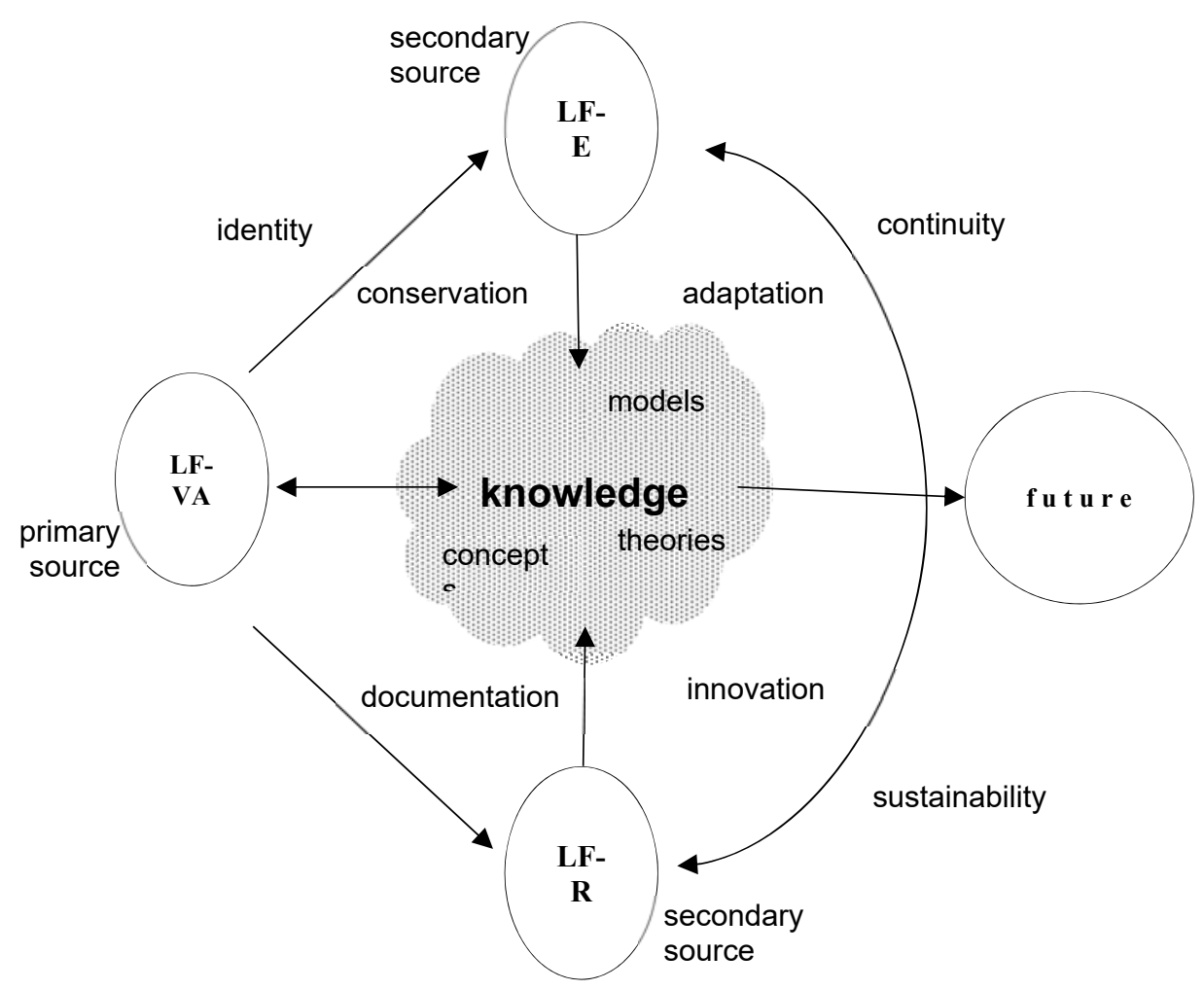

Figure 5: Components of the case of guidelines/learning from vernacular architecture and interlinks between these components.

\subsection{Case study}

The model, elaborated in the previous section, contains different ways of learning from vernacular architecture. In this section of the study, a case study in which two of these ways are followed together is given. Göynük, one of the traditional Anatolian settlements, was chosen for the sample. Located in the province of Bolu in the north-west of Turkey, Goynuk is a settlement dates back to 1200s B.C. Within the scope of the study, two suggested routes (LF-VA, LF-R) in the model were followed (Fig. 6) For this purpose, firstly, literature research was conducted, academic studies on settlement were examined and two publications were reached in the field of architecture. The first of these is a doctoral dissertation entitled "Göynük the historical site; religious and civil architecture heritage conservation problems and issues for new building" (Erdem [10]). The second publication on the settlement is an article titled "Spatial Structure of Traditional Göynük Houses and Recommendations for Conservation" (Dikmen and Toruk [11]). 


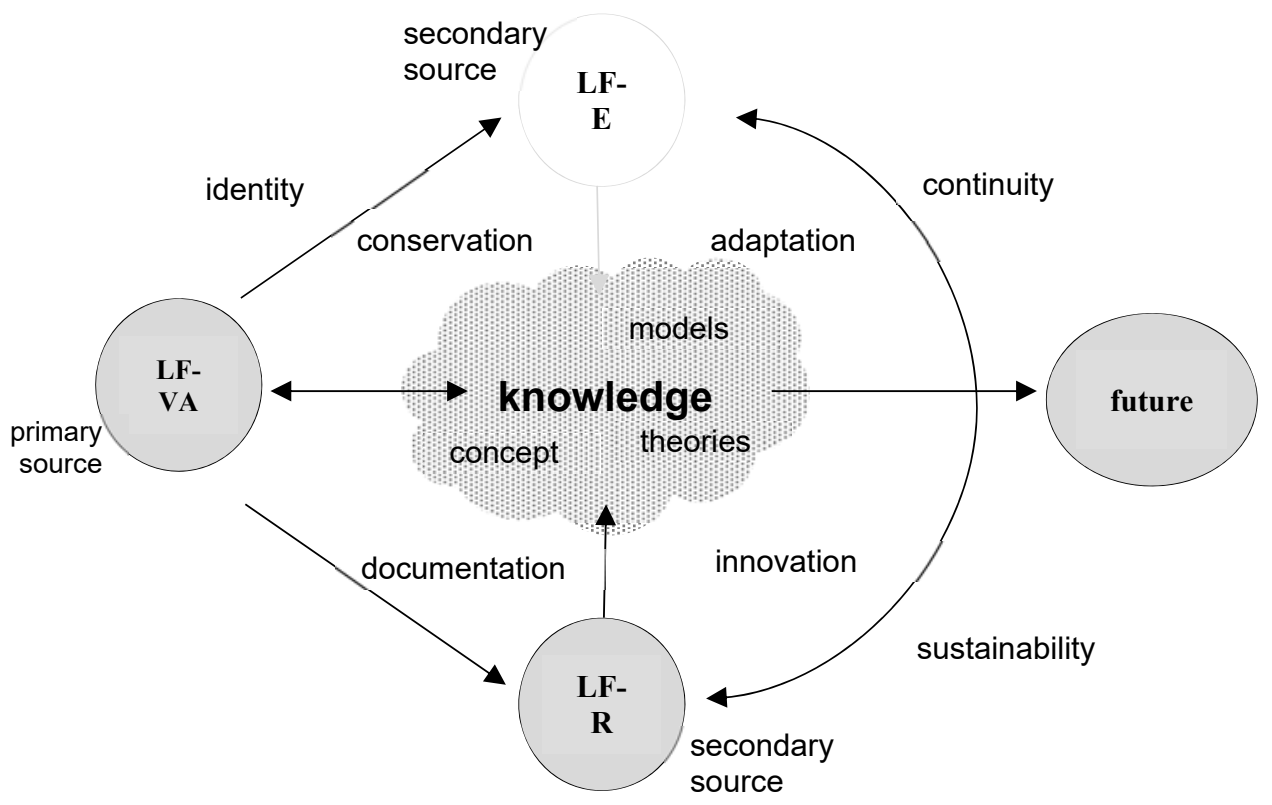

Figure 6: Routes followed for the case.

After the literature review, a study trip was made to the settlement. The settlement was examined under the guidance of a local official, and maps, photographs and videos were identified. After the trip, the original features of the settlement were examined under various headings (such as spatial organisation, structural elements, construction system, materials and originality issues in architecture) and their determinations, observations and interpretations were systematically brought together.

Both the above-mentioned studies on the settlement of Göynük provide various determinations related to the settlement, argue that it should be protected and make various recommendations for this. Beyond these, the aim of this study is to take a new step in the future. After the idetification studies, future interpretations of how vernacular architecture knowledge could be useful for the future were tried to be created, sketches and collages were prepared. suggestions were developed based on the assumption that some situations within the original structure of vernacular architecture examples may exist in contemporary architecture and that this continuity may also answer some problems (such as scale, context) of contemporary architecture. For example, a proposal is based on a critical reading of existing settlements; instead of being disconnected from its environment (as in today's examples), a fragmented and widespread understanding of mass (as in traditional Göynük houses) that relate to its environment (as in the past) has been proposed instead of vertical and one-piece blocks (Fig. 7(a)). Another study criticizes the reduction of the form with a formalist approach while making use of traditional architecture. Instead, it is emphasized that the "essence" should be sought and that the culture of life, climate interpretation and the use of materials in vernacular architecture can be guiding (Fig. 7(b)). 


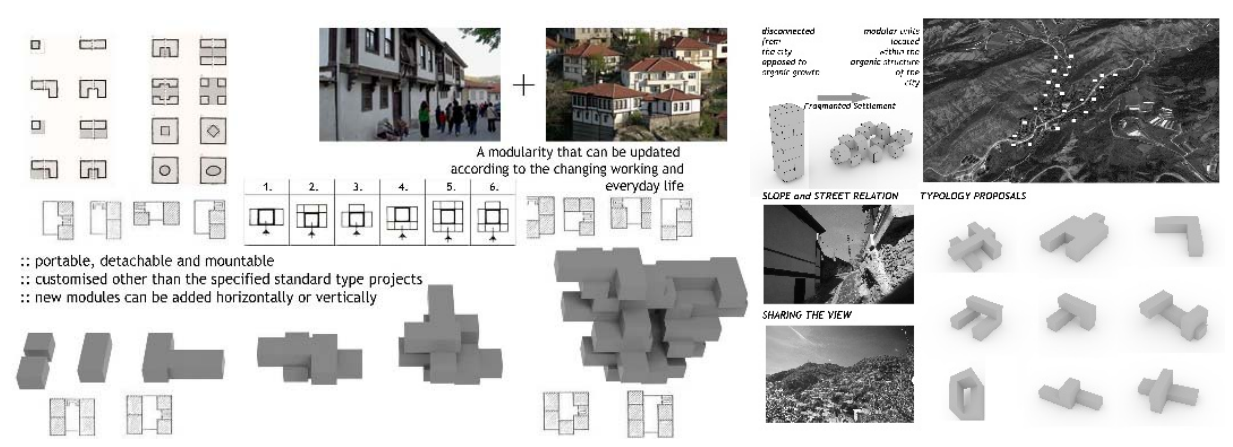

Figure 7: Examples of posters.

As a result of the study, it is seen that using key concepts can be a powerful way to feed on vernacular architecture. Thus, a method based on conceptualization was implemented in order to benefit from vernacular architectural knowledge. Within this frame, the interpretations about the future were constructed over concepts/searches, and in the posters (Fig. 7), various images corresponding to the concepts were used, and the knowledge revealed was concretized through the images.

\section{CONCLUSION}

Architecture is related with the world's most ancient and profound knowledge. Learning from this treasure accumulated for centuries by rising above the layers of previous knowledge has globally been the basis of architecture profession and architecture education. Likewise, this research was grounded on this basis and it aimed to discover alternative routes for the future-oriented learning by consulting the vernacular architecture knowledge of past era. Besides, the authors of this study aimed to provide a model that can make alternative situations visible for not only their future research but also for other researchers aiming to learn from vernacular architecture. As a result of these aims, a guideline-model that displayed the main dynamics of learning from vernacular architecture and interconnections between these dynamics has been formed. Developing the suggested model and experiencing the alternative roads in this model are only a few of the methods that can be suggested for future studies. The authors of this paper hold the belief that another alternative suggestion for future researchers as a follow-up is to analyze directions and methods to transfer to the future knowledge that is united via a range of methods.

\section{REFERENCES}

[1] Yürekli, F., Mimarlık-Mimarlı̆̆ımız, Yem Yayın: Istanbul, 2011.

[2] Masrour, M. \& Karbaschi, M., Comprehending vernacular architecture in the architectural educational system in Iran. American Journal of Civil Engineering and Architecture, 3(2), pp. 45-51, 2015.

[3] Rashid, M. \& Ara, D.R., Modernity in tradition: reflections on building design and technology in the Asian vernacular. Frontiers of Architectural Research, 4, pp. 46-55, 2015.

[4] Velinga, M., The noble vernacular. The Journal of Architecture, 18(4), pp. 570-590, 2013.

[5] Rapaport, A., Kültür Mimarlık Tasarım, çev. S. Batur, Yapı Yayınları: Istanbul, 2004. 
[6] Hillier, B. \& Hanson, J., The Social Logic of Space, Cambridge University Press: New York, 1984.

[7] Meir, I.A. \& Roaf, S.C., The future of vernacular towards new methodologies for the understanding and optimization of the performance of vernacular buildings. Vernacular Architecture in the Twenty-First Centrury: Theory, Education and Practice, eds L. Asquith \& M. Vellinga, pp. 215-30, 2006.

[8] Ozorhon, G \& Ozorhon, I.F., Learning from experience in architecture: Fathy, Correa, Cansever. International Review of Social Sciences and Humanities, 11, pp. 41-53, 2016.

[9] Asquith, L. \& Vellinga, M., Introduction, Vernacular Architecture in the Twenty-First Centrury: Theory, Education and Practice, eds L. Asquith \& M. Vellinga, pp. 1-20, 2006.

[10] Erdem, A., Göynük the Historical Site; Religious and Civil Architecture Heritage Conservation Problems and Issues for New Building (Unpublished doctoral dissertation), YTU Institute of Sciences: Istanbul, 1996.

[11] Dikmen, Ç.B. \& Toruk, F., Spatial structure of traditional Göynük houses and recommendations for conservation. Afyon Kocatepe Üniversitesi Sosyal Bilimler Dergisi, 17(1), pp. 99-128, 2015. 